\title{
Pengaruh Kinerja Tutor Asrama Terhadap Komunikasi Interpersonal Mahasiswa Universitas Negeri Gorontalo
}

\author{
Tuti Wantu ${ }^{1}$, Jumadi Mori Salam Tuasikal ${ }^{2}$ \\ Jurusan Bimbingan dan Konseling, Fakultas Ilmu Pendidikan, Universitas Negeri Gorontalo, Indonesia ${ }^{1,2}$ \\ tutiwantu20@gmail.com
}

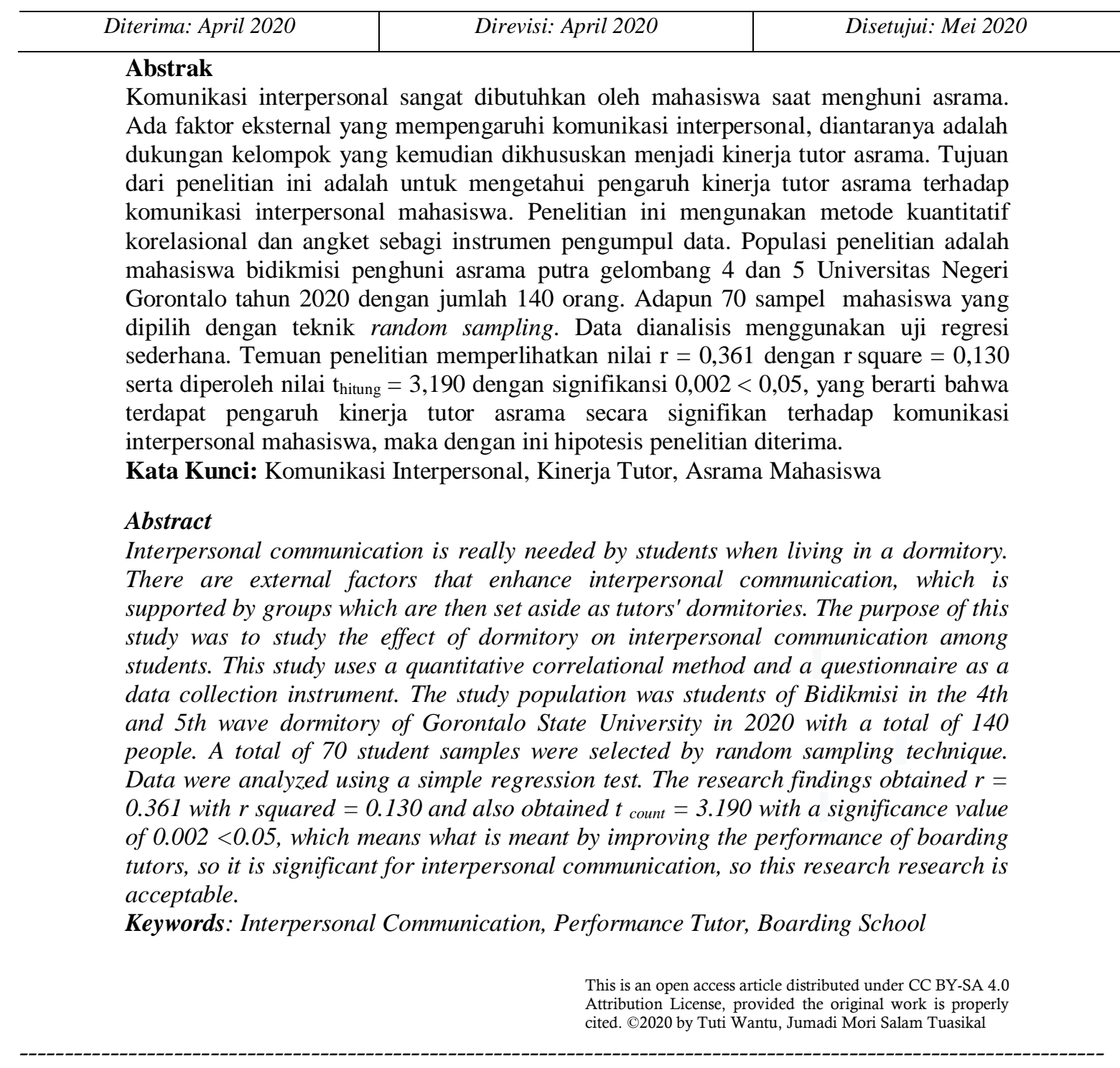

\section{PENDAHULUAN}

Perguruan tinggi memiliki peran penting dalam menyiapkan mahasiswa yang memiliki modal kemampuan akademik, profesionalitas yang mantap serta mampu mengembangkan ilmu pengetahuan dan teknologi serta berusaha menerapkannya demi meningkatkan kesejahteraan masyarakat, bangsa dan negara. Oleh karenanya mahasiswa dalam proses pendidikan akan diarahkan untuk meningkatkan potensinya secara optimal, agar menjadi individu yang beriman dan bertaqwa kepada tuhan yang maha esa, berakhlak 
mulia, sehat, berilmu, mandiri, berkepribadian dan berkarakter mulia sehingga menjadi warga negara yang membanggakan.

Dalam mencapai target tersebut, sejumlah program pendidikan diracang oleh perguruan tinggi untuk menjawab setiap kebutuhan yang dapat mendukung mahasiswa guna meningkatkan kualitasnya, baik secara pribadi, sosial, belajar maupun karier. Salah satu program pendidikan yang seringkali kita temukan yang dirancang untuk mendukung proses akademik mahasiswa adalah sekolah berasrama (boarding school). Sekolah berasrama merupakan sekolah yang mewajibkan siswanya untuk bertempat tinggal di asrama selama mengikuti program pengajaran (Hamdana \& Alhamdu, 2015).

Keberadaan sekolah berasrama yang dibuat oleh perguruan tinggi, menurut Wahab (2008) dapat dijadikan sebagai wadah sosial yang memiliki fungsi edukatif, sosial, moral, dan kader. Lebih lanjut menurutnya fungsi-fungsi tersebut dapat terlihat saat berlangsungnya aktifitas di asrama yaitu, menjadi tempat belajar yang kondusif khususnya untuk belajar kehidupan, menjadi wadah untuk meningkatkan keterampilan sosial sehingga penghuninya mampu beradaptasi dan mampu menghargai perbedaan individu, dijadikan wadah untuk menjalin integritas kepribadian dan moral keagamaan, dan dijadikan wahana untuk melatih penghuninya tentang keterampilan kepemimpinan. Senada dengan itu, Araujo dan Murray (2010) dari hasil penelitiannya terungkap bahwa mahasiswa yang menghuni asrama berkontribusi terhadap meningkatnya indeks prestasi di atas rata-rata melebihi yang tidak menghuni asrama. Melihat kondisi ini, seakan mengkonfirmasi bahwa ada harapan besar dibalik terselengaranya program berasrama yang dapat menghantarkan mahasiswa berjiwa unggul dan berdaya saing.

Dalam penyelengaraan kegiatan berasrama mahasiswa dituntut untuk memiliki kemampuan dalam bersosialisasi dan beradaptasi di setiap kondisi dan situasi serta dengan berbagai individu yang ada di asrama agar tercapainya hubungan yang harmonis antara sesama penghuni. Dalam hal ini, salah satu keterampilan yang harus dimiliki oleh mahasiswa adalah kemampuan komunikasi interpersonal yang baik. Menurut Devito (2011) komunikasi interpersonal diartikan sebagai komunikasi antara dua orang yang bertujuan untuk saling mengenal, berhubungan, saling mempengaruhi, bermain, dan saling membantu. Lebih lanjut menurutnya komunikasi interpersonal yang efektif ditandai dengan enam aspek efektivitas yakni: empati, keterbukaan, sikap positif, kesetaraan, sikap mendukung dan pemahaman. Individu yang memiliki kemampuan berkomunikasi yang efektif akan lebih mudah dalam menyelesaikan masalah, terutama konflik-konflik dengan orang lain.

Interaksi komunikatif seperti inilah yang akan mendatangkan kenyamanan mahasiswa dalam beraktifitas di asrama sehingga mendatangkan dampak positif dan menambah kemauan mahasiswa untuk aktif dalam mengikuti setiap kegiatan belajar maupun tugas-tugas tambahan di asrama. Dari hal tersebut, komunikasi dari pengirim, penerima, dan pesan adalah pondasi dari komunikasi yang sukses, tetapi juga dapat membuat kesalahpahaman.

Pada kenyataannya pihak pengirim bisa gagal untuk mengirimkan pesan atau tidak benar untuk mengirimkan pesan yang bermanfaat atau bisa jadi pihak penerima mengubah atau salah mengartikan pesan tersebut dikarenakan lemahnya keterampilan komunikasi 
interpersonal yang dimiliki, dan menjadikan pesan tidak akurat atau berubah sehingga mendatangkan banyak kasus yang bermasalah. Hal tersebut didukung oleh beberapa penelitian yang memperjelas bahwa masih banyak individu yang mengalami masalah komunikasi interpersonal yang telihat dalam penelitian Das (2010), Salmita (2010), Berliana (2012), Arliani (2014), serta menurut Tuasikal, Mudjiran, dan Nirwana (2016) bahwa kemampuan komunikasi interpersonal yang mengalami gangguan perlu untuk dientaskan atau ditingkatkan ke arah yang lebih baik lagi. Jika tidak dikhawatirkan berpotensi individu tidak lagi menghormati nilai-nilai yang terkandung di dalam etika berkomunikasi yang biasanya dianut oleh manusia yang berbudaya dan beragama. Sudah barang tentu hal tersebut juga berlaku bagi setiap mahasiswa yang sedang berasrama untuk menyadarinya.

Sehubungan dengan permasalahan komunikasi interpersonal, terdapat banyak faktor yang mempengaruhi timbulnya permasalah tersebut, diantaranya adalah pengaruh kelompok dan hubungan dengan lingkungan (Rakhmat: 2015 \& Devito: 2011). Jika kita menempatkan faktor tersebut dalam kerangka kegiatan berasrama maka terlihat bahwa setiap stekholder yang berada dalam ruang lingkup asrama seperti tim pengelola asrama, tutor, narasumber, mahasiswa penghuni asrama maupun masyarakat sekitar akan memiliki kontribusi terhadap komunikasi interpersonal.

Merujuk kepada pembahasan tersebut peneliti tertarik untuk mengkaji pelaksanaan kegiatan boarding school di asrama putra berprestasi Universitas Negeri Gorontalo yang menjadi wadah untuk mendidik mahasiswa penerima beasiswa bidikmisi. Seperti yang kita ketahui bahwa pengelolaan bidikmisi milik perguruan tinggi tersebut menerima prestasi terbaik 1 se-Indonesia oleh Direktorat Jenderal Pembelajaran dan Kemahasiswaan (Ditjen Belmawa) pada tahun 2018 (bidikmisi.com). Sehingga perlu kiranya untuk memahami keberlanjutan peran sentralnya dalam proses mendukung pengembangan kualitas mahasiswa. Maka penelitian ini secara khusus bertujuan untuk mengetahui seberapa besar pengaruh kinerja tutor asrama putra berprestasi terhadap komunikasi interpersonal mahasiswa bidikmisi gelombang 4 dan 5 Universitas Negeri Gorontalo tahun 2020.

\section{METODE}

Metode penelitian ini adalah kuantitatif dengan pendekatan korelasional. Populasi dalam penelitian ini adalah seluruh mahasiswa penghuni asrama putra penerima beasiswa bidikmisi gelombang 4 dan 5 Universitas Negeri Gorontalo tahun 2020 sebanyak 140 mahasiswa, dan sampel yang diambil adalah 50\% (Arikunto: 2006) yang dipilih dengan teknik random sampling yakni berjumlah 70 mahasiswa. Metode pengumpulan data menggunakan instrumen angket dengan skala model likert dalam mencari data kinerja tutor (X) dan data komunikasi interpersonal mahasiswa (Y). Teknik analisis regresi sederhana dibantu menggunkan program SPSS versi 20.00.

\section{HASIL TEMUAN}

Hipotesis yang menjadi pijakan dalam penelitian ini yaitu "terdapat pengaruh kinerja tutor secara signifikan terhadap komunikasi interpersonal mahasiswa". Hipotesis tersebut diuji dengan menggunakan analisis regresi sederhana antara kinerja tutor terhadap 
komunikasi interpersonal mahasiswa yang menghasilkan koefisien regresi sebagaimana dapat dilihat pada Tabel 1 .

Tabel 1. Hasil Regresi Sederhana

\begin{tabular}{lcc}
\hline \multicolumn{1}{c}{ Varibel Penelitian } & $\mathbf{R}$ & R square $\left(\mathbf{r}^{\mathbf{2}}\right)$ \\
\hline Kinerja Tutor & 0,361 & 0,130 \\
Komunikasi Interpersonal & & \\
\hline
\end{tabular}

Dari hasil analisis regresi sederhana (r) didapat nilai 0,361 yang menunjukkan bahwa terdapat hubungan antara kinerja tutor dengan komunikasi interpersonal mahasiswa ke arah hubungan yang positif. Hal ini menandai bahwa semakin tinggi tingkat kinerja tutor maka semakin meningkatkan prestasi komunikasi interpersonal mahasiswa. Sedangkan untuk hasil $r$ square $\left(r^{2}\right)$ sebesar 0,130 yang berarti bahwa kontribusi kinerja tutor terhadap komunikasi interpersonal mahasiswa sebesar 13\%, sedangkan sisanya dipengaruhi oleh variable yang lain.

Disamping itu dilakukan uji signifikansi yang bertujuan untuk menjelaskan model regresi dan tigkat pengaruh antara variabel kinerja tutor $(\mathrm{X})$ dapat menjelaskan variasi nilai komunikasi interpersonal (Y) dengan mengunakan besaran nilai $\mathrm{F}$ dan nilai $\mathrm{T}$, sebagaimana dapat dilihat pada Tabel 2:

Tabel 2. Hasil Uji Signifikansi

\begin{tabular}{lccc}
\hline \multicolumn{1}{c}{ Varibel Penelitian } & $\mathbf{F}_{\text {hitung }}$ & $\mathbf{F}_{\text {tabel }}$ & Sig \\
\hline \multirow{2}{*}{$\begin{array}{l}\text { Kinerja Tutor } \\
\text { Komunikasi Interpersonal }\end{array}$} & 10,176 & 7,02 & 0,002 \\
\cline { 2 - 4 } & $\mathbf{T}_{\text {hitung }}$ & $\mathbf{T}_{\text {tabel }}$ & Sig \\
\cline { 2 - 4 } & 3,190 & 2,382 & 0,002 \\
\hline
\end{tabular}

Berdasarkan perhitungan diperoleh nilai $\mathrm{F}_{\text {hitung }}=10,176>\mathrm{F}_{\text {tabel }} 7,02(0,01)$ dengan tingkat signigfikan $=0,002<0,05$ maka dapat disimpulkan bahwa model regresi dapat dipakai untuk memprediksi variabel komunikasi interversonal $(\mathrm{Y})$. Selanjutnya diperoleh nilai $t_{\text {hitung }}=3,190>t_{\text {tabel }} 2,382$ dengan nilai signifikansi $0,002<0,05$, maka hipotesis penelitian diterima, yang berarti bahwa ada pengaruh yang nyata (signifikan) antara kinerja tutor terhadap meningkatnya komunikasi interpersonal mahasiswa bidikmisi penghuni asrama putra.

\section{PEMBAHASAN}

Hasil penelitian ini menunjukkan bahwa besaran kontribusi kinerja tutor terhadap komunikasi interpersonal mahasiswa 13\%, artinya dukungan kinerja tutor memberikan sumbangan yang signifikan terhadap komunikasi interpersonal mahasiswa bidikmisi Universitas Negeri Gorontalo. Sebagaimana pendapat Rakhmat (2015) yang meyakini bahwa komunikasi interpersonal dipengaruhi oleh faktor persepsi interpersonal, atraksi interpersonal, dan hubungan interpersonal dengan orang lain yang dapat memberi pengaruh pada perubahan sikap dan perilaku seseorang.

Terlebih lagi menurut Handayani (2019) bahwa meningkatnya komunikasi interpersonal akan menjadi instrumen yang sangat penting bagi individu agar 
mengekspresikan pemahaman dan konsep dirinya dalam pergaulan maupun lingkungan sosialnya.

Selanjutnya pendapat Sururi \& Nasihin (2009) menjelaskan bahwa asrama yang baik sudah seharusnya didukung oleh kelompok yang bertugas mengelola dan bertanggungjawab terhadap pelaksanaan sistem asrama. Jika melihat struktur pengelolaan asrama putra bidikmisi Universitas Negeri Gorontalo sesuai dengan Pedoman Pengelolaan dan Pembinaan Mahasiswa Bidikmisi di asrama berprestasi Universitas Negeri Gorontalo tahun 2018 terdiri dari Rektor, Wakil-wakil rektor, Tim pengelola fasilitas, Tim pengelola program, dan Tutor, yang pada dasarnya memiliki kinerjanya masing-masing sesuai dengan tugas dann fungsi yang telah diatur.

Sesuai dengan penelitian ini bahwa dukungan kelompok yang dimaksud lebih diarahkan kepada kinerja tutor asrama yang pada kesehariannya tinggal di asrama untuk mengawasi mahasiswa bidikmisi penghuni asrama setiap hari. Moheriono (2012) menyatakan bahwa kinerja merupakan gambaran mengenai tingkat pencapaian pelaksanaan suatu program kegiatan atau kebijakan dalam mewujudkan sasaran, tujuan, visi dan misi organisasi yang dituangkan melalui perencanaan strategis suatu organisasi. Lebih lanjut Sedarmayanti (2001), menyatakan bahwa kualitas kinerja dapat diukur melalui aspek; 1). Kualitas kerja, 2). Ketepatan waktu, 3). Inisiatif, 4) Kemampuan dan 5) Komunikasi.

Berikut gambaran kinerja tutor melalui rincian tugas dan kewenangan yaitu: 1) Memberikan dukungan, pendampingan pada penghuni asrama, 2) Membimbing penghuni asrama dalam kehidupan sehari-hari, 3) Mengevaluasi kegiatan berasrama, 4) Membantu tim pengeloladalam pengawasan terhadap asrama, 5. Melaporkan seluruh tugas dan kewajiban kepada ketua asrama (Tim Penyusun: 2018). Selaras dengan itu Sururi dan Nasihin (2009) mengungkapkan bahwa kinerja tutor biasa dilakukan antara lain: 1) mengarahkan agar tugas/program berasrama dapat dikerjakan dengan cepat dan sebaikbaiknya terutama jika berbentuk tugas kelompok; 2) mengawasi sikap dan tingkah laku sesuai peraturan dan kode etik asrama; 3) memfasilitasi penghuni asrama yang kesulitan (kiriman dari orang tua terlambat, sakit, dsb) agar saling membantu; 4) meringankan kecemasan orang tua terhadap anaknya; 5) dapat melakukan pengajaran secara aktif dan partisipatif dengan berbagai cara yang efektif untuk mengendalikan tingkah laku yang kurang baik serta meningkatkan kemampuan mahasiswa secara optimal.

Melihat begitu sentralnya kinerja tutor asrama seperti yang diungkapkan sebelumnya mulai dari dukungan secara emosional, memberi dorongan semangat serta motivasi, kehidupan bersosial sosial, hingga belajar. Dengan adanya hal demikian maka akan membuat suasana berasrama menjadi lebih tertib, mampu beradaftasi, menyesuaikan diri secara baik, terbangun rasa percaya diri, dapat berpikir secara positif, kondusif, mampu memanagemen waktu dengan baik dan terkontrol. Maka tidak perlu diragukan lagi bahwa kontribusinya terhadap meningkatnya komunikasi interpersonal siswa sangat diperlukan.

Selain itu perlu juga untuk mengkaji dari berbagai aspek diantaranya seperti identifikasi pribadi calon penghuni. Hal yang perlu dimaknai adalah latar belakang budaya, karakter dan juga kesiapan calon penghuni terkait dengan minat atau motivasi masuk 
asrama, dapat dilakukan melalui evaluasi dari materi yang sudah ada, pengembangan materi, dan redesain strategi serta dukungan fasilitas dan organisasi.

\section{SIMPULAN}

Berdasarkan hasil temuan dan pembahasan penelitian, maka dapat dikemukakan kesimpulan bahwa kinerja tutor asrama putra memberikan pengaruh secara signifikan terhadap komunikasi interpersonal dilihat dari nilai $r=0,361$ dan $r$ square $=0,130$ yang bermakna bahwa kontribusi kinerja tutor sebesar 13\% terhadap komunikasi interpersonal, dengan nilai perolehan $\mathrm{t}_{\text {hitung }}=3,190>\mathrm{t}_{\text {tabel }}=2,382$ pada signifikansi $0,002<0,05$. Artinya, apabila semakin tinggi kinerja tutor asrama maka semakin meningkat komunikasi interpersonal mahasiswa.

\section{DAFTAR PUSTAKA}

Araujo, D. P. \& Murray, J. (2010). "Estimating the E_ects of Dormitory Living on Student Performance. University of Wisconsin-La Crosse". Economics Bulletin, Vol. 30 (1): Hal. 866-878.

Arikunto, S. (2006). Metodelogi penelitian. Yogyakarta: Bina Aksara.

Arliani. (2014). Pengaruh Komunikasi Interpersonal Keluarga dan Motivasi Belajar Terhadap Hasil Belajar Ekonomi Siswa di SMA Negeri”. (Tesis tidak diterbitkan) Universitas Negeri Padang, Indonesia.

Berliana, S. A. (2012). Hubungan antara Komunikasi Interpersonal dalam Keluarga dengan Pamahaman Moral pada Remaja. Jurnal, Vol. 2 (3): Hal. 12.

Bidikmisi.com. (2018, desember). Penghargaan terbaik 1 pengelola bidikmisi 2018 diberikan ke Universitas Negeri Gorontalo. 2 April 2020. Website: http://www.bidikmisi.com/2018/12/penghargaan-terbaik-ipengelola.html?m=1

Das, I. (2010). Harapan Siswa terhadap Peranan Orangtua untuk Mengentaskan Masalah Mereka dalam Pelayanan Konseling: Studi pada SMA Negeri di Kota Padang. (Tesis tidak diterbitkan) Universitas Negeri Padang, Indonesia.

DeVito, J. A. (2011). Komunikasi Antarmanusia. Jakarta: Karisma Publishing Group.

Hamdana, F., \& Alhamdu. (2015). Subjective Well-Being Siswa MAN 3 Palembang yang Tinggal di Asrama. Jurnal Psikologi Islami, Vol. 1 (1), Hal. 95-104. Retrieved from http://jurnal.radenfatah.ac.id/index. php/psikis/article/view/560

Handayani, S., Yusmansyah, \& Mayasari, S. (2019). Hubungan Antara Konsep Diri dengan Komunikasi Interpersonal pada Siswa. ALIBKIN Jurnal Bimbingan $\begin{array}{lllll}\text { Konseling, Vol. } & 7 & \text { (3). } & \text { Retrieved } & \text { from }\end{array}$ http://jurnal.fkip.unila.ac.id/index.php/ALIB/article/view/19039/13573

Moeheriono. (2012). Pengukuran Kinerja Berbasis Kompetensi. Jakarta: Raja Grafindo Persada.

Rakhmat, J. (2015). Psikologi Komunikasi. Bandung: Remaja Rosdakarya. 
Salmita, N. (2010). Masalah yang Dialami Siswa Akselerasi SMA di Kota Padang dan Peranan Guru Pembimbing. (Tesis tidak diterbitkan) Universitas Negeri Padang, Indonesia.

Sedarmayanti. (2001). Sumber Daya Manusia dan Produktivitas Kerja. Bandung: Mandar Maju.

Sururi \& Nasihin, S. (2010). Manajemen Peserta Didik. Bandung: Alfabeta.

Tim Penyusun. (2018). Pedoman Pengelolaan dan Pembinaan Mahasiswa Bidikmisi di Asrama Berprestasi Bidikmisi Universitas Negeri Gorontalo. Gorontalo. Universitas Negeri Gorontalo.

Tuasikal, J. M. S., Mudjiran, M., \& Nirwana, H. (2016). Pengembangan Modul Bimbingan dan Konseling untuk Meningkatkan Kemampuan Komunikasi Interpersonal Siswa. Konselor, Vol. 5 (3), Hal. 133-138.

Wahab, R. (2008). Asrama mahasiswa = lab sosial. Kedaulatan Rakyat. 2 Maret. hal. 1 \& 23. 